\title{
Buscando leer la historia mundial desde Nuestra América
}

Hernán G. H. Taboada Universidad Nacional Autónoma de México

Resumen

Existen en América Latina muchos y ya tradicionales reclamos por el abandono del eurocentrismo historiográfico, y en algún grado se han alcanzado resultados en cuanto a los discursos nacionales y regionales se refiere. Sin embargo, seguimos siendo deudores de la vieja historia "universal" originada en Europa, con su exponente clave que es Hegel pero también una difusión capilar en los libros escolares, enciclopedias y toda obra de vulgarización.

Esta persistencia se debe a la hegemonía cultural de los grupos criollos en América Latina, que tienen una muy peculiar relación con Europa y su cultura. Su visión histórica, que hemos denominado "eurocriollismo", sigue predominando mientras en la misma Europa ya ha sido desplazada. Las propuestas para una historia "mundial" policéntrica, que ya tienen varias décadas en otros países, apenas son conocidas en América Latina.

El artículo aspira a definir brevemente dicha historia universal eurocriolla, a presentar brevemente las corrientes de la historia mundial, a criticar algunas lecturas supuestamente alternativas desde Nuestra América (Leopoldo Zea, Enrique Dussel) y a señalar el camino que falta recorrer. 
Palabras clave: Historiografía, América Latina, eurocentrismo historiográfico, historia mundial, filosofía latinoamericana, criollismo

\section{Abstract}

In Latin America, there are now many traditional protests of the abandonment of historiographical eurocentrism which, to some degree, have achieved national and regional discourse. However, we continue to be indebted to the old "universal" history originated in Europe. It's key proponent is Hegel, but also the capillary diffusion of school books, encyclopedias, and other vulgar works.

This persistence is due to a cultural hegemony of Creole groups in Latin America that have a very particular relationship with Europe and its culture. Their historical vision, which we have denominated "eurocriolism," continues to dominate, while it has been displaced in Europe itself. The proposals for a polycentric world history which now has been in other countries for decades, are just becoming known in Latin America.

The article aspires to briefly define that universal eurocreole history, to briefly present currents in world history, to criticize some so-called alternative lectures to "Nuestra América," (Leopoldo Zea, Enrique Dussel) and to signal the path yet to be travelled.

Keywords: Historiography, Latin America, Historiographic éurocentrism, Word History, Latinamerican philosophy, Criollismo

Zn un artículo que publicamos en 2002 (125-142) Carlos Tur - $y$ yo opinábamos, entre otras cosas, que la ciencia histórica en América Latina había indudablemente progresado durante las últimas décadas, pero lo había hecho casi exclusivamente en el campo de los estudios nacionales. Lo decíamos tras el intento de esbozar un panorama de la producción latinoamericana sobre historia mundial, que concluyó en la poca importancia y el enfoque euro- 
céntrico que la dominaba. Hoy veo de forma ligeramente distinta el asunto: en parte por mi mayor conocimiento del entorno, en parte por los cambios ocurridos desde entonces. Aunque mínimamente, han aparecido iniciativas de todo tipo en los países que se han concretado en la creación de centros de estudio, revistas, páginas electrónicas y eventos sobre mundos históricos más allá del panorama nacional, que incluyen Asia y África. Por otro lado, en forma unánime o casi, el enfoque eurocéntrico es cuestionado desde todos los sectores.

Todo ello es mérito de una combinación de tendencias ecuménicas y regionales. Para empezar con lo más general, citemos las comunicaciones y las mayores posibilidades de acceso a publicaciones, de sistemas de aprendizaje audiovisuales, de viaje y de intercambio; por ejemplo, hoy podemos leer en línea repertorios básicos que eran un arcano para la generación anterior; las iniciativas de estudiar más allá de lo propio pueden contar con jóvenes que aprenden idiomas hasta hace poco considerados exóticos y de alcance imposible; también, hay un cambio en los centros de poder: ya es un lugar común (objeto de las especulaciones más variadas en los medios de comunicación, la literatura popular y la academia) señalar que China e India están desplazando al mundo occidental. Es cierto que hasta hace relativamente poco se hacían comentarios parecidos inspirados en el ascenso de Japón, pero el peso específico de este país en el mundo era y es mucho menor que el de los dos gigantes asiáticos hoy emergentes. Cabe decir que a estas estrellas se van ańadiendo otras potencias menores pero discernibles, como Indonesia, Turquía, Irán y Sudáfrica.

Mucho menos subrayado es un fenómeno que nos toca más de cerca: la presencia cada vez mayor de estos países emergentes en América Latina. Esto, ya en sí, es un objeto de estudio, que aquí sólo voy a repasar brevemente. El caso de China es especialmente notable, pues se aprecia una visibilidad cotidiana inescapable en 
objetos de consumo, programas de televisión, culinaria, modas e inmigrantes, no obstante, los otros países no están del todo ausentes: recientemente ha sido lanzado en Buenos Aires el equivalente turco del Instituto Cervantes, Dante Alighieri o Goethe Institut (un centro destinado a promover la lengua y cultura de los pueblos turcos); Irán tiene presencia en Bolivia a través de programas culturales y un canal de televisión; Arabia Saudita está detrás de una red de mezquitas que se extiende silenciosamente en las capitales latinoamericanas; por su parte, India hace inversiones en la industria pesada. Paralelamente, se están creando o consolidando centros de estudios latinoamericanos en países como Turquía o Marruecos. Las diásporas traen a nuestros países individuos de regiones lejanas, a veces profesionistas, académicos o estudiantes con preparación suficiente como para colaborar en la difusión de su cultura. Sin embargo, los cambios no sólo vienen de afuera. Esta presencia deriva, entre muchas otras cosas, del peso que los países latinoamericanos están adquiriendo en los asuntos mundiales, es decir, en sus dimensiones demográficas, económicas, políticas y culturales. En México, es un florecimiento que guarda alguna analogía con los que se dieron a comienzos de los siglos XIX y XX, que, por un lado, llevaron a nuestra independencia política y, por otro, promovieron la formulación de proyectos intelectuales en torno al modernismo, al idealismo antipositivista y a los nacional-populismos. En ambos casos se contó con un interés análogo, aunque mucho más reducido, por el mundo extraeuropeo, asuntos que en su momento he investigado.

En estrecha relación con lo anterior, en el comienzo del siglo XXI, se ha visto por primera vez la amplia manifestación de un sentimiento popular distinto al de las elites criollas o al de los grupos intelectuales muy ligados a Europa, ambos discursos que estábamos acostumbrados a oír. Es lógico que ello derive en una visión distinta del pasado, lo cual es particularmente notable en los países 
andinos y en los movimientos indigenistas, que hacen de Europa un objeto particular de su odio:

Europa no sólo mata culturas y creencias, Europa también mata personas con sus armas por todo el mundo, hoy como hace cinco siglos [...] hoy se sigue en lo mismo, en "exportar" recursos naturales para alimentar a Europa, en "exportar" recursos naturales como millones de metros cúbicos de gas a argentinos o a brasileros de ascendencia europea para que con confort tengan mejor industria que aquí, mientras en viviendas y colegios del altiplano no hay calefacción (Katari, 2013: 12, 14).

Estas frases de un intelectual boliviano son expresivas del repudio, por primera vez extendido entre nosotros, hacia el eurocentrismo criollo. Pero lo son no solamente en su violencia, sino también en su error, porque, a mi juicio, equivocan el blanco (valga el juego de palabras) y, sin querer, incorporan la categoría básica de lo que pretenden criticar: la misma noción esencialista de Europa. Esto es lo que debemos observar en muchas manifestaciones análogas de crítica al eurocentrismo: siguen siendo retóricas e ideológicas más que científicas (hasta viscerales y majaderas, si nos guiamos por la cita anterior); prisioneras de las categorías, cronologías, analogías, metáforas y de los juicios de valor reunidos por la vieja historiografía eurocéntrica, incluso hasta deudora de ésta para el recuento mismo de los hechos.

Semejante dependencia es un flanco débil para los grupos empeñados en cambiar la posición que ocupamos en el sistema mundial y en desplazar a las elites criollas a él ligadas, sobre todo porque esto ya no sólo es un asunto de pocos gobiernos o algunos grupos radicales sino una tendencia general. El empeńo conlleva políticas económicas y sociales, un manejo independiente, alejado del tradicional, en las relaciones exteriores, pero también una sólida propuesta cultural y, dado el tradicional historiocentrismo de 
toda reflexión latinoamericana, una nueva lectura del pasado, que derribe las últimas barricadas de la historiografía criolla, que fue clasista, racista y sigue siendo eurocéntrica. Al respecto, una polifonía, o un batifondo ruidoso, se ha dejado escuchar en los últimos años: fantásticas disquisiciones indigenistas, una teoría del actual sistema internacional que toma en cuenta voces ajenas a las imperiales, aunque sea en ecos y circunloquios, o estudios de la historia de la región basados en interpretaciones alternativas a las de matriz eurocéntrica. Insisto, sin embargo, en la falta de una teoría similar sobre la historia mundial, que estamos hasta ahora obligados a derivar de manuales reiterativos, sean o no de acento crítico.

Recogemos aquí un fruto paradójico del pecado antes aludido y que seguimos purgando: el aldeanismo, con su coda de ignorancia sobre el mundo que nos rodea, la situación internacional presente y la historia que hemos arrastrado. La deuda con las investigaciones ajenas es tributaria de la ignorancia aldeana, por lo cual la cultura de los manuales escolares, de las enciclopedias, de los libros de divulgación y de los programas de televisión sigue centrada en $\mathrm{Eu}$ ropa. Véase como prueba el auge que tienen las historias populares escritas desde un ángulo conservador y eurocéntrico, cuyo eterno motivo es el "ascenso de Occidente". El último ejemplar de dichos especímenes es el volumen Civilización: Occidente y los otros, del escocés Niall Ferguson y su equipo, publicado en inglés en 2011 y que ya se encuentra en su versión castellana en las librerías latinoamericanas. Dicha obra repite la vieja versión culturalista sobre el triunfo de Occidente y tanto su tono como la bibliografía sugieren la ilusión de una sólida ciencia a la que la mayoría no dejará de rendir tributo, a mi juicio inmerecido.

Aunque en sectores marginales, estos son avances debidos a un entorno mundial y a movimientos sociales favorables, pero con un abundante arrastre de defectos: lo que observamos en la historiografía se podría predicar desde muchos otros terrenos. No obstan- 
te, lo que aconsejo es cautela y aprendizaje, pero además con una mirada hacia episodios de nuestra historia intelectual pasada. Esto ha faltado a menudo: como los estudiosos de mundos exóticos suelen desconocer la historia de las ideas latinoamericanas, no es malo recordar un viejo círculo que éstas suelen recorrer, en el cual se aprecia cómo, prometiendo cambiar las cosas, cada generación reprocha a la anterior el desconocimiento de la realidad propia y la afición al libro extranjero, el resultado suele limitarse al abandono no sólo de los libros frecuentados por los padres, sino también de las conclusiones, por escasas que sean, a los que éstos llegaron, de lo que deriva, inevitablemente, un entusiasmo no por la realidad propia sino por otros libros extranjeros (Cfr. Nelle, 1997: 107-125).

En el caso que comento, el culto de la última generación se ha dirigido a las variantes de la crítica poscolonial y posmoderna: se nos ha repetido sobre la mirada imperial, la ansiedad occidental, las estrategias de apropiación, los grandes relatos, las deformaciones de la mirada, los artefactos, el patriarcalismo y los ocultamientos. ${ }^{1}$ Bienvenida sea esta apertura, en cuyo haber se contabilizan muy positivos resultados de los enfoques feministas y los estudios culturales, que han permitido caer en cuenta de antiguos atavismos, mientras las filosofías de la historia parecen querer salir de la trampa conceptual en que siempre han circulado. Los cultivadores de estas parcelas, sin embargo, empeñados en descifrar textos cada vez más dificultosos, no parecen tener tiempo ni ganas de hurgar en los documentos ni buscar "lo que realmente ocurrió", para retomar la frase tan famosa como vejada. Por ello nos hemos quedado con los resultados a los que los arribaron autores extranjeros, mayoritariamente originarios del mundo anglo y francófono. Es

${ }^{1}$ No todo este vocabulario, pero una parte sí, aparece en la compilación hecha por Edgardo Lander: La colonialidad del saber: eurocentrismo y ciencias sociales, perspectivas latinoamericanas (2005), una valiosa empresa crítica desde categorías sociológicas y filosóficas. 
el caso de la condena al orientalismo entre nosotros: raro es quien haya leído directamente la literatura orientalista que el tan citado Edward Said criticó (y que conoció sólo parcialmente) para tomarlo como punto de partida y no de llegada.

Al mismo tiempo, han caído en el olvido los esfuerzos que en otras épocas hicimos por comprender esos mundos extraños y el curso de la historia mundial. Nadie, por supuesto, hoy va a tomar en serio los Estudios indostánicos (1917) de José Vasconcelos, pero sí merecen atención los artículos que José Mariátegui escribió en los años veinte sobre las revoluciones turca y china o los libros, que no por insuficientes carecen de valor, que en los años sesenta empezaron a circular en Latinoamérica en torno a otros países como Asia y África: colecciones sobre economía, política y literatura editadas en Argentina, Cuba y México. Eran breves, eran traducciones de colecciones europeas análogas o inspiradas en una extendida editorial rusa, su mérito fue indudable. Por otro lado, el centro de estudios que más resultados cosechó fue el Centro de Estudios de Asia y África de El Colegio de México, que tuvo como gemela a la Asociación Latinoamericana de Estudios de Asia y África. Ambos nacieron en la misma coyuntura (ańos 1975 y 1976) que surge del entusiasmo por las victoriosas luchas descolonizadoras del tercer Mundo.

Igualmente importante y significativo fue el hecho de que en esos ańos aparecieron algunos intentos por escribir una historia del mundo desde nuestra circunstancia. Leopoldo Zea (1912-2004), desde los años cincuenta, se fue acercando progresivamente a la interpretación de la historia de América al publicar América en la historia en 1957. En esta obra buscaba enlazar la historia latinoamericana con la de los otros pueblos sometidos de Asia y África. ${ }^{2}$ Lamentablemente sabía muy poco de estos pueblos y sabía poco

${ }^{2}$ Una empresa que Zea veía como análoga a la de los intelectuales espańoles de la generación de Ortega y Gasset, volcada a "revisar la historia española en función con la historia universal, es decir occidental" (Zea, 1957: 152). 
de la historia propiamente dicha, que sólo había aprendido desde las categorías de Arnold Toynbee, por lo que su obra se fue toda en disquisiciones que no salían de la cultura mexicana criolla. En sus numerosos libros siguientes, Zea continuó el mismo camino circular que siguen hollando sus sucesores, también numerosos.

A pesar de sus fallas, el mérito de Zea fue inspirar una obra de otra índole: De la revolución agrícola a la termonuclear (1967), de Darcy Ribeiro (1922-1997), la primera parte de una obra de historia universal que continuó con Las Américas y la civilización (1970) y Los brasileños (1972). Un intento parecido al del brasileño, menos sistemático pero mucho más fundamentado, estuvo detrás de los escritos del argentino José Luis Romero, quien se fue alejando de las épocas antigua y medieval, su primera vocación, para volcarse a América Latina, la cual apenas resulta aludida, en pocas y marginales referencias, en su escrito El ciclo de la revolución contemporánea (1948), mientras que en su último libro, Latinoamérica: las ciudades y las ideas (1976), es tema central (aunque visto en sus orígenes europeos y en su contexto ecuménico que no sale del Occidente). Romero sí conocía las fuentes y la tela de la cual se hace historia, por lo que, quizás, al final de su vida reparó en el eurocentrismo de su mundo intelectual.

Estos autores y sus obras deberían situarse en una cadena, cuya investigación está por hacerse, acerca de los intentos de escribir historias universales en América Latina y donde probablemente el primer episodio sea el ensayo del argentino Vicente Fidel López, que versa sobre los resultados con que las naciones antiguas contribuyeron al desarrollo de la civilización (1845) y probablemente todos ellos no fueran sino calcos de las compilaciones tradicionales, con alguna nota de color local. Sintomático es entonces el emprendimiento de los ańos sesenta y setenta. No creo que acertara Romero en sus intuiciones básicas ni que lo hiciera como historiador el antropólogo Darcy, cuya obra yace en relativo olvido; sin embargo. hay que rescatar que en los años críticos en torno a 1968, en pleno auge de la teoría de la 
dependencia, se emprendiera tal esfuerzo por situar a América Latina en el curso de la historia global. Extender la mirada para escudriñar los caminos históricos por los que se creó la mentada dependencia era lo que reclamaba dicha teoría. Eso hicieron posteriormente dos autores, Andre Gunder Frank e Immanuel Wallerstein, muy cercanos ambos a América Latina pero estadounidenses ambos. Fueron, sin embargo, los únicos: en general, la vivaz polémica en torno a la teoría de la dependencia giró únicamente sobre temas latinoamericanos y la obra magna de Wallerstein, que podía haber dado lugar a abundantes discusiones desde América Latina, considerando el lugar que a esta región asigna dicho autor en el desarrollo del moderno sistema mundial, fue muy citada pero poco evaluada críticamente. (Stern, 1988: 829-872).

Es decir que, como muchos otros, el entusiasmo de los años sesenta y setenta por los mundos extraeuropeos y extracriollos se desvaneció: aquellas viejas ediciones hoy reaparecen en las librerías de viejo, muchas iniciativas quedaron en la nada y, peor todavía, los nuevos investigadores dedicados a una historia más global han perdido el lazo con la realidad latinoamericana. Volvemos entonces a los párrafos iniciales: ha habido cambios, pero no los suficientes para vencer una vigorosa inercia y, en este contexto, el campo historiográfico sigue ocupado preponderantemente por las historias nacionales (con algún entusiasmo último por la historia latinoamericana), y sigue aunado a un conocimiento muy tradicional de la historia clásica y la europea; todo con desatención del "resto". Lo primero es inexcusable, lo segundo sería sumamente útil si su estudio no estuviera ligado a los viejos relatos eurocéntricos, lo tercero censurable sin más. Quienes quieren innovar, los grupos que he mentado como interesados por el mundo exterior, actúan al margen del sistema oficial y no se insertan en una tradición consolidada ni en iniciativas previas, por precarias que fueran. Tal situación tiene ciertas ventajas pues se emprende sin ataduras 
ideológicas, pero, al mismo tiempo, tiene el demérito de aislarse de los problemas regionales.

Ante este panorama, el llamado es, una vez más, a ensayar un relato propio, elaborado desde Nuestra América con elementos originales. Cada época escribe su historia universal, cada civilización lo hace, dijeron Goethe y Arnold Toynbee, y América Latina ya ha empezado a aparecer como una civilización distinta entre los autores que estudian la historia como el juego entre los grandes conjuntos culturales que así denominan. No que esté de acuerdo con este esquema, de poca utilidad analítica, pero sería ejercicio revelador pispiar en estos panoramas el lugar que nos asignan, desde la asimilación apresurada en los viejos manuales, hasta la duda en el libro de Ferguson antes citado y la etiquetación aparte, tanto en la influyente El choque de civilizaciones (1996) de Samuel Huntington como en un reciente artículo de Régis Debray en la revista Nexos (2013, 28-38). Tal distinción es indicativa de las tendencias antes comentadas: el peso que estamos adquiriendo y las nuevas tendencias políticas y culturales. Las mismas suponen para nosotros el compromiso de ponernos por fin a escribir nuestra historia universal, que en primer lugar no se llamaría así, sino historia mundial, global o ecuménica.

Para ello habría que enlazar el mayor conocimiento de otras partes del mundo, que antes subrayé como novedad auspiciosa, con el estudio de la realidad latinoamericana. Permitiéndome hablar de mí, he intentado en algunos foros esbozar un esquema de dicha historia en conferencias, en un curso, en un artículo (2012: internet). El hilo conductor ha sido el enlazamiento de la historia americana a las otras civilizaciones del Viejo Mundo, el cual permite descubrir los contactos, los aportes culturales y las influencias migratorias; al mismo tiempo subraya la relatividad temporal de los lazos con Europa occidental, un momento en nuestra historia que al parecer se está dejado atrás. $\mathrm{Al}$ releer lo escrito, tomo 
conciencia de la enormidad de lo que falta realizar, las infinitas lecturas por emprender y la necesidad imprescindible de hacerlo en colaboración con otros.

Buscamos socios pues. Como forma de alentarlos, viene a cuento una reflexión sobre una reflexión de Richard Palmer recientemente leída. En 1954, este autor decía que los europeos podían dedicarse al estudio de la revolución en cada uno de sus países, pero que los estadounidenses estaban capacitados para estudiar la revolución atlántica en su conjunto, porque ellos fueron colonizados por gentes de toda Europa y no están ligados particularmente a un país determinado de ella (Palmer, 1963: 8). Los latinoamericanos, interrumpo yo aquí, hemos sido colonizados desde todas las regiones del mundo ¿No podríamos derivar de ello el privilegio de poder escribir una verdadera historia del mundo?

\section{Bibliografía}

Debray, Régis, 2013, “Occidente: cuadro clínico”, Nexos, núm. 424 (abril), pp. 28-38.

Lander, Edgardo, 2005, La colonialidad del saber: eurocentrismo y ciencias sociales, perspectivas latinoamericanas, Buenos Aires, CLACSO.

Nelle, Florian, 1997, "París, los pasajes atlánticos y el discurso de la imitación”, Estudios, año 5, núm. 9, pp. 107-125.

Palmer, R. R., 1963, "The world revolution and the West", en Peter Amann (ed.), The eighteenth-century revolution, French or Western?, Boston, D. C. Heath and Company, pp. 1-9.

Stern, Steve J., 1988, "Feudalism, capitalism, and the world-system in the perspective of Latin America and the Caribbean", The American Historical Review, vol. 93, núm. 4, pp. 829-872. 
Taboada, Hernán G. H., 2012, "Para 'reorientar' la historia de América: en busca de sus relaciones con la ecúmene euroafroasiática”, Astrolabio, nueva época, núm. 9, disponible: http:// revistas.unc.edu.ar/index/php/astrrolabio/

Zea, Leopoldo, 1957, América en la historia, México, FCE, p. 152.

(Artículo recibido el 7 de enero de 2014; aceptado el 25 de febrero de 2014) 
